\title{
Assessing the vertical distribution of leaf chlorophyll content in a maize crop
}

\author{
Sophie MOULIN, Frédéric BARET, Cécile BATAILLE and Nadine BRUGUIER
}

INRA - Unité Climat, Sol, et Environnement (CSE)

Bât. Climat - Site Agroparc - Domaine Saint-Paul, 84914 Avignon cedex 9 , FRANCE

$$
\begin{aligned}
& \text { Corresponding author : Sophie Moulin } \\
& \text { e-mail : sophie.moulin@avignon.inra.fr } \\
& \text { tel: (+33) } 432722413 \\
& \text { fax: (+33) } 432722362
\end{aligned}
$$

Topic : C07 Vegetation and Environmental Monitoring

The vertical distribution of the chlorophyll in a plant canopy is not uniform as shown through numerous measurements. This leads to bias in the chlorophyll content (Cab) estimation both at leaf and canopy levels. In the frame of the CHRIS/PROBA project, Cab measurements were performed using a SPAD device on each leaves of several plants along the maize crop cycle over few fields. Those measurements, as well as the surface measurements and the leaf insertion height measurements give the vertical distribution of chlorophyll pigments within the canopy.

The chlorophyll content is higher for the middle leaves than for the top and bottom leaves of the plant. The impact of chlorophyll vertical distribution on the canopy reflectance response was investigated. For this purpose, the SAIL model was applied on multiple layers, reproducing the observed chlorophyll profile.

Results are presented with emphasis the interest of taking into account the chlorophyll distribution along the crop development. Using vertical chlorophyll profiles to simulate the radiometric answer of a crop is a way to improve the accuracy in crop characteristics estimations. 